\title{
Physiological effects of high-flow oxygen in tracheostomized patients
}

\author{
Daniele Natalini ${ }^{1}$, Domenico L. Grieco' ${ }^{1}$ Maria Teresa Santantonio', Lucrezia Mincione², \\ Flavia Toni ${ }^{1}$, Gian Marco Anzellotti ${ }^{1}$, Davide Eleuteri ${ }^{1}$, Pierluigi Di Giannatale ${ }^{2}$, Massimo Antonelli ${ }^{1}$ \\ and Salvatore Maurizio Maggiore $2^{2^{*}}$ (i)
}

\begin{abstract}
Background: High-flow oxygen therapy via nasal cannula (HFOT NASAL $_{\text {L }}$ increases airway pressure, ameliorates oxygenation and reduces work of breathing. High-flow oxygen can be delivered through tracheostomy (HFOT TRACHEAL), but its physiological effects have not been systematically described. We conducted a cross-over study to elucidate the effects of increasing flow rates of HFOT TRACHEAL on gas exchange, respiratory rate and endotracheal pressure and to compare lower airway pressure produced by HFOT NASAL $_{\text {and HFOT }}$ TRACHEAL.
\end{abstract}

Methods: Twenty-six tracheostomized patients underwent standard oxygen therapy through a conventional heat and moisture exchanger, and then HFOT TRACHEAL through a heated humidifier, with gas flow set at 10, 30 and $50 \mathrm{~L} /$ min. Each step lasted 30 min; gas flow sequence during HFOT TRACHEAL was randomized. In five patients, measurements were repeated during HFOT TRACHEAL before tracheostomy decannulation and immediately after during HFOT NASAL. In each step, arterial blood gases, respiratory rate, and tracheal pressure were measured.

Results: During HFOT TRACHEAL, $\mathrm{PaO}_{2} / \mathrm{FiO}_{2}$ ratio and tracheal expiratory pressure slightly increased proportionally to gas flow. The mean [ $95 \%$ confidence interval] expiratory pressure raise induced by $10-\mathrm{L} / \mathrm{min}$ increase in flow was 0.2 $[0.1-0.2] \mathrm{cmH}_{2} \mathrm{O}(\rho=0.77, p<0.001)$. Compared to standard oxygen, HFOT TRACHEAL limited the negative inspiratory swing in tracheal pressure; at $50 \mathrm{~L} / \mathrm{min}$, but not with other settings, HFOT TRACHEAL increased mean tracheal expiratory pressure by (mean difference [95\% Cl]) $0.4[0.3-0.6] \mathrm{cmH}_{2} \mathrm{O}$, peak tracheal expiratory pressure by $0.4[0.2-0.6] \mathrm{cm}_{2} \mathrm{O}$, improved $\mathrm{PaO}_{2} / \mathrm{FiO}_{2}$ ratio by 40 [8-71] $\mathrm{mmHg}$, and reduced respiratory rate by $1.9[0.3-3.6]$ breaths/min without $\mathrm{PaCO}_{2}$ changes. As compared to HFOT TRACHEAL, HFOT NASAL produced higher tracheal mean and peak expiratory pressure (at $50 \mathrm{~L} / \mathrm{min}$, mean difference [95\% Cl]: 3 [1-5] $\mathrm{cmH}_{2} \mathrm{O}$ and 4 [1-7] $\mathrm{cmH}_{2} \mathrm{O}$, respectively).

Conclusions: As compared to standard oxygen, $50 \mathrm{~L} / \mathrm{min}_{\mathrm{i}} \mathrm{HFOT}_{\text {TRACHEAL }}$ are needed to improve oxygenation, reduce respiratory rate and provide small degree of positive airway expiratory pressure, which, however, is significantly lower than the one produced by HFOT NASAL. $_{\text {. }}$

Keywords: Oxygen inhalation therapy, Tracheostomy, Respiratory insufficiency, Mechanical ventilator weaning, Positive end-expiratory pressure

\section{Background}

Nasal high-flow oxygen therapy (HFOT $\mathrm{HASAL}_{\mathrm{N}}$ ) has been proposed to treat acute hypoxemic respiratory failure

\footnotetext{
*Correspondence: salvatore.maggiore@unich.it

${ }^{2}$ Department of Medical, Oral and Biotechnological Sciences, School of Medicine and Health Sciences, Section of Anesthesia Analgesia, Perioperative and Intensive Care, SS. Annunziata Hospital, Gabriele d'Annunzio University of Chieti-Pescara, Via dei Vestini, 66100 Chieti, Italy Full list of author information is available at the end of the article
}

[1-4], to facilitate weaning from mechanical ventilation [5-8] and to prevent hypoxemia during endotracheal intubation $[9,10]$.

With $\mathrm{HFOT}_{\text {NASAL}}$, up to $60 \mathrm{~L} / \mathrm{min}$ of heated and humidified air/oxygen mixture are continuously delivered to the patient through specifically designed nasal prongs [11]. Unlike standard oxygen, high flows limit dilution of inhaled gas mixture, thus enabling more accurate delivery of the set fraction of inspired oxygen $\left(\mathrm{FiO}_{2}\right)$ [12]. 
HFOT $_{\text {NASAL }}$ increases end-expiratory lung volume due to the generation of flow-dependent airway positive pressure, with highest values reached at end-expiration with closed mouth [13-15]. The continuous high flow washes $\mathrm{CO}_{2}$ out from upper airways, reducing anatomical dead space and work of breathing [16]. Active heating/humidification and the comfortable interface improve comfort related to airway dryness and optimize device tolerability [16-18].

High-flow oxygen can be delivered also through tracheostomy ( $\mathrm{HFOT}_{\mathrm{TRACHEAL}}$ ), but its mechanism of action and physiological effects appear different and have not been thoroughly elucidated $[19,20]$. We conducted a randomized cross-over study to assess the effects of HFOT $_{\text {TRACHEAL }}$ administered at different gas flow rates on gas exchange, tracheal pressure, and respiratory rate, and to establish whether the increase in airway pressure generated by high-flow oxygen is different when administered by nasal cannula or tracheostomy.

\section{Methods}

The present study was carried out in the general intensive care unit (ICU) of a tertiary-care university hospital in Rome between September 2016 and September 2017, after a preliminary study conducted on a previous cohort of patients to assess the feasibility of tracheal pressure measurement in critically ill patients [21]. The study protocol was approved by the local institutional review board; written informed consent was obtained by all patients or next of kin, according to the ethics committee recommendations.

\section{Patients}

We studied critically ill tracheostomized patients with no hemodynamic instability who had been weaned from mechanical ventilation, had been spontaneously breathing with no ventilatory support for at least $24 \mathrm{~h}$ and were receiving tracheal oxygen according to the prescription of the attending physician. All enrolled patients had received single-dilator percutaneous tracheostomy with PercuTwist ${ }^{\circledR}$ technique (Rüsch, Kernen, Germany): the procedure was performed by an intensivist under bronchoscopy, which confirmed that the puncture was taking place between the first and second, or second and third, tracheal rings [22, 23]. Non-inclusion criteria were age $<18$ years, pregnancy, recent tracheal, esophageal, neck or thoracic surgery, presence of pneumothorax/chest drainage. For safety reasons, patients with partial pressure of arterial oxygen to nominal $\mathrm{FiO}_{2}$ ratio $\left(\mathrm{PaO}_{2} / \mathrm{FiO}_{2}\right)$ below $100 \mathrm{mmHg}$ and/or respiratory rate $>45$ breaths per minute during standard oxygen were not enrolled.

\section{Procedures}

After study inclusion, each patient received for $30 \mathrm{~min}$ standard oxygen through tracheostomy with a heat and moisture exchanger (Tracheolife II HME, Mallinckrodt,
United Kingdom), with oxygen flow set by the attending physician (standard oxygen step, maximal $\mathrm{O}_{2}$ flow $8 \mathrm{~L} /$ $\min$ ).

Patients subsequently underwent high-flow oxygen: gas flow was provided by the dedicated module of an ICU ventilator (EvitaXL or EvitaInfinity, Drager, Lubeck, Germany), inspired gas was actively conditioned by heated humidifier set at $37^{\circ} \mathrm{C}$ (HH MR850, Fisher \& Paykel Healthcare, NewZealand, absolute humidity provided $44 \mathrm{mgH}_{2} \mathrm{O} / \mathrm{L}$ ) and delivered through the specifically designed interface (Optiflow $^{\text {TM }}$ Tracheostomy interface OPT870, Fisher \& Paykel Healthcare, New-Zealand). Three oxygen flow rates with the HFOT $_{\text {TRACHEAL }}$ device were tested in random order, for $30 \mathrm{~min}$ each: $10 \mathrm{~L} / \mathrm{min}, 30 \mathrm{~L} / \mathrm{min}$, and $50 \mathrm{~L} / \mathrm{min}$. No wash-out period was applied between these interventions. Although $10 \mathrm{~L} / \mathrm{min}$ cannot be considered as 'high-flow therapy', this step allowed (A) to better characterize the effects of increasing flow rate with the same device on analyzed endpoints, and (B) to compare standard oxygenation device (closed system through a heat a moisture exchanger) and $\mathrm{HFOT}_{\text {TRACHEAL }}$ (open system) at similar gas flow rate, highlighting the difference between these techniques. The randomization sequence was provided by S.A.S. random allocation software. $\mathrm{FiO}_{2}$ was set to obtain a $\mathrm{SpO}_{2}$ between 92 and 98\% (88-92\% in patients with $\mathrm{PaCO}_{2} \geq 45 \mathrm{mmHg}$ during standard oxygen). Changes in the $\mathrm{FiO}_{2}$ over the course of the study were discouraged and allowed only whether clinically unavoidable.

\section{Measurements}

At the end of each step, hemodynamic parameters, arterial blood gases and $\mathrm{SpO}_{2}$ were recorded. To estimate $\mathrm{PaO}_{2} /$ $\mathrm{FiO}_{2}$ during standard oxygen, delivered $\mathrm{FiO}_{2}$ was calculated using a previously described formula [24]:

$$
\begin{aligned}
\mathrm{FiO}_{2}= & \text { (oxygen flow rate in liters per minute } * 0.03) \\
& +0.21 .
\end{aligned}
$$

At study entry, a sterile, disposable 18-gauge catheter (15/25-cm length according to patient's height; 1-mm diameter; BD, CareFusion corporation, San Diego, CA, USA) connected to a differential pressure transducer was inserted in the trachea $(2 \mathrm{~cm}$ away from carina, with the distance between tracheal stoma and carina measured on the chest X-ray) and secured to the skin with an adhesive tape. At the end of each study step, endotracheal pressure was recorded continuously for $3 \mathrm{~min}$ by a dedicated software at a sample rate of $200 \mathrm{~Hz}$ (Kleis-Tek, ICU lab, Bari, Italy). Pressure signals were offline-reviewed to assess respiratory rate and compute mean expiratory pressure (between the end of inspiration and the beginning of the following inspiration), peak expiratory and inspiratory pressure (maximal and minimal pressure achieved over the whole respiratory cycle, respectively). All these 
parameters were measured for all breaths in the 3-min recording and values were averaged for each study step.

In a subgroup of five patients who underwent tracheostomy decannulation after study inclusion and during the ICU stay, the experimental protocol was repeated on the day of decannulation, both during HFOT $_{\text {TRACHEAL }}$ and during $\mathrm{HFOT}_{\mathrm{NASAL}}$ after decannulation. Briefly, when the tracheal cannula was removed, the catheter for tracheal pressure measurement was hold in situ and the stoma was covered with gauze and adherent sealing tape (percutaneous tracheostomy maintains subcutaneous tissue integrity and elasticity) [25]. After medication, absence of leaks through the stoma was assessed by hand while the patient spontaneously vocalized and coughed. This approach was clinically useful for assessing patient's tolerance to mouth/nose breathing and represented a unique opportunity to evaluate lower airway pressure during $\mathrm{HFOT}_{\mathrm{NASAL}}$. In these 5 patients, $\mathrm{HFOT}_{\mathrm{TRACHEAL}}$ and HFOT $_{\text {NASAL }}$ with three flow settings $(10,30$ and $50 \mathrm{~L} / \mathrm{min}$ ) were applied for 20 -min periods in sequential order, just before and immediately after tracheostomy decannulation. No wash-out period was applied between the interventions. Heated humidifier settings were kept unchanged. Towards the end of each period, tracheal pressure tracings were recorded and were offline-analyzed to compute mean and peak expiratory pressure, as previously described.

\section{End-points}

Primary endpoint was to compare ratio of arterial oxygen partial pressure to nominal $\mathrm{FiO}_{2}\left(\mathrm{PaO}_{2} / \mathrm{FiO}_{2}\right)$ in the different study steps. Main secondary endpoints were to analyze the effects of the tested settings on respiratory rate, endotracheal pressure and $\mathrm{PaCO}_{2}$. Furthermore, we aimed at establishing whether tracheal pressure is different when high-flow oxygen is delivered through tracheostomy or nasal cannula, at similar flow rates.

\section{Statistical analysis}

Descriptive data are expressed as number and percentage and continuous data as median [interquartile range]. Because of the limited sample, adopting a conservative approach, all data were analyzed with non-parametric tests. Paired comparisons between the study steps were performed with the Wilcoxon sum of ranks test and mean differences [95\% confidence interval] are displayed for most significant results. Correlation was assessed with Spearman's rank-order correlation: $\rho$ and the $p$ value are reported. Analysis on the mean expiratory pressure rise induced by increasing gas flow was performed with linear regression: the slope and the $p$ value of the relationship are reported. Inter-individual variability was rated with the coefficient of variation, computed as the ratio of standard deviation to mean of the measurements [26]. Results with two-tail $p \leq 0.05$ were considered significant. Statistical analysis was performed with SPSS 20.0 (IBM SPSS Statistics for Windows, Version 20.0. Armonk, NY, USA).

\section{Sample size}

Clinical data on the effects of HFOT TRACHEAL $_{\text {are lim- }}$ ited to a single exploratory study [20]: this hampered any estimation of the adequate sample needed to provide sufficient statistical power to the study. Because previous investigations with similar design demonstrate that 15-20 patients studied in a cross-over fashion represent an adequate sample to draw conclusions on similar physiological endpoints $[13,15,18,20,27]$, adopting a conservative approach, we planned to enroll 25 patients.

\section{Results}

Twenty-six patients were enrolled and analyzed. Demographics and most relevant clinical characteristics are reported in Table 1 . In the standard oxygen step, median oxygen flow was $4[3,4] \mathrm{L} / \mathrm{min}$ and median estimated $\mathrm{FiO}_{2}$ was 0.33 [0.33-0.37]. No patient experienced changes in heart rate or arterial blood pressure over the course of the study. The sequence of HFOT TRACHEAL $_{\text {. }}$ interventions did not affect $\mathrm{PaO}_{2} / \mathrm{FiO}_{2}(\rho=0.05, p=0.69)$ nor respiratory rate $(\rho=0.002, p=0.99)$.

\section{Gas exchange and respiratory rate}

These results are displayed in Fig. 1.

During HFOT $_{\text {TRACHEAL }}$ increasing flow rates yielded improvement in oxygenation, markedly between 10 and $30 \mathrm{~L} / \mathrm{min}(p<0.001)$ and mildly between 30 and $50 \mathrm{~L} / \mathrm{min}$ $(p=0.07)$.

As compared to standard oxygen, HFOT TRACHEAL $50 \mathrm{~L} /$ min, but not 30 nor $10 \mathrm{~L} / \mathrm{min}$, increased $\mathrm{PaO}_{2} / \mathrm{FiO}_{2}$ ratio: median [Interquartile range] 307 [241-390] mmHg vs. 277 [247-344] $\mathrm{mmHg}, p=0.01$; mean difference [95\% CI] 40 [8-71] mmHg) (Fig. 1a).

When compared to standard oxygen, HFOT $_{\text {TRACHEAL }}$ $50 \mathrm{~L} / \mathrm{min}$ led to a slight reduction in respiratory rate (24 [21-29] breaths/min vs. 26 [22-33] breaths/ min, $p=0.02)$, without changes in $\mathrm{PaCO}_{2}$ (32 [26-36] mmHg vs. 31 [27-37] $\mathrm{mmHg}, p=0.43$ ) (Fig. 1b, c). The mean reduction $[95 \% \mathrm{CI}]$ in respiratory rate yielded by HFOT $_{\text {TRACHEAL }} 50 \mathrm{~L} / \mathrm{min}$ was 1.9 [0.3-3.6] breaths/min and was proportional to respiratory rate during standard oxygen (i.e., greater in patients with higher respiratory rate, $\rho=0.43 p=0.03)$. No differences in $\mathrm{PaCO}_{2}$ were detected between the studied conditions (Fig. 1b, c). 
Table 1 Baseline characteristics of enrolled patients

\begin{tabular}{ll}
\hline No. of patients & 26 \\
Age, years & $57[48-71]$ \\
Female sex, no. (\%) & $4(15)$ \\
Height, cm & $175[168-180]$ \\
Body weight, $\mathrm{kg}$ & $75[70-85]$ \\
Body mass index, kg/m² & $25[24-28]$ \\
SAPS II & $46[41-60]$ \\
Patients with history of COPD, no. (\%) & $5(19)$ \\
ICU admission, no. (\%) & \\
Medical & $12(46)$ \\
Surgical & $7(27)$ \\
Trauma & $7(27)$ \\
Cause of prolonged need for mechanical ventilation, no (\%) \\
Respiratory failure & $8(31)$ \\
Traumatic brain injury & $7(27)$ \\
Non-traumatic brain injury & $11(42)$ \\
Length of mechanical ventilation before enrollment, & $11[8-13]$ \\
days & \\
Glasgow coma scale at enrollment & $10[6-15]$ \\
PaO $/$ /FiO & \\
Tracheal cannula inner diameter, mm standard oxygen, mmHg & $238[197-311]$ \\
Tracheal cannula external diameter, mm & $9[8.5-10]$ \\
Length of ICU stay, days & $12.3[12.3-12.3]$ \\
In-ICU mortality, no. (\%) & $20[14-26]$ \\
\hline
\end{tabular}

Results are displayed as medians [interquartile range], if not otherwise specified SAPSII simplified acute physiology score 2 at ICU admission, COPD chronic obstructive pulmonary disease, ICU intensive care unit

${ }^{a}$ Measured during the standard oxygen step of the experiment

\section{Tracheal pressure}

These results are displayed in Fig. 2.

In the three HFOT $_{\text {TRACHEAL }}$ steps, mean and peak expiratory pressures were proportional to the delivered gas flow ( $p<0.001$ for all comparisons). The mean [95\% CI] expiratory pressure rise induced by $10-\mathrm{L} / \mathrm{min}$ increase in flow was $0.2[0.1-0.2] \mathrm{cmH}_{2} \mathrm{O}(\rho=0.77$, $p<0.001)$. As compared to standard oxygen, $50 \mathrm{~L} / \mathrm{min}$, but not other HFOT $_{\text {TRACHEAL }}$ settings, led to an increase in peak and mean expiratory pressures: peak pressure 1.8 [1.4-2.2] $\mathrm{cmH}_{2} \mathrm{O}$ vs. 1.3 [0.9-2] $\mathrm{cmH}_{2} \mathrm{O}, p=0.001$; mean pressure $1.2[1-1.5] \mathrm{cmH}_{2} \mathrm{O}$ vs. $0.8[0.5-1.3] \mathrm{cmH}_{2} \mathrm{O}$, $p<0.001$ (Fig. 2a, b). Mean differences [95\% CI] in peak and mean expiratory pressure between HFOT $_{\text {TRACHEAL }}$ $50 \mathrm{~L} / \mathrm{min}$ and standard oxygen were $0.4[0.2-0.6] \mathrm{cmH}_{2} \mathrm{O}$ and $0.4[0.3-0.6] \mathrm{cmH}_{2} \mathrm{O}$, respectively. Both peak and mean expiratory pressures were lower at $\mathrm{HFOT}_{\text {TRACHEAL }}$ $10 \mathrm{~L} / \mathrm{min}$ than during standard oxygen (both $p<0.001$ ).

All HFOT TRACHEAL $_{\text {settings yielded less negative tra- }}$ cheal peak inspiratory pressure, as compared to standard oxygen $(p<0.001$ for all the comparisons): this effect was magnified at $50 \mathrm{~L} / \mathrm{min}$ (Fig. 2c).

\section{Comparison with HFOT ${ }_{\text {NASAL }}$}

Five patients underwent tracheostomy decannulation within their stay in ICU, and received HFOT $_{\text {TRACHEAL }}$ and $\mathrm{HFOT}_{\text {NASAL }}$ before and after the procedure. Samples of tracheal pressure tracings are displayed in
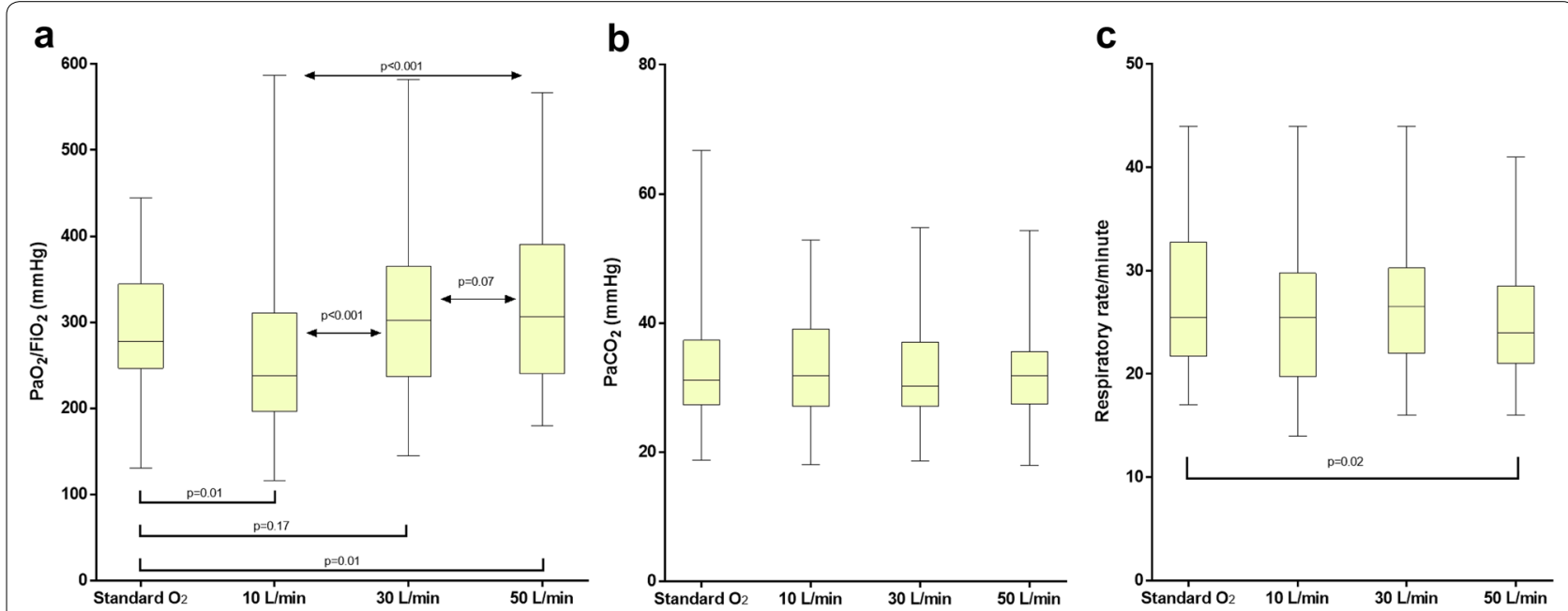

Fig. $1 \mathrm{PaO}_{2} / \mathrm{FiO}_{2}(\mathbf{a}), \mathrm{PaCO}_{2}$ (b) and respiratory rate (c) in the four study steps. Results are displayed as median, interquartile range, maximum and minimum. With HFOT TRACHEAL device, $\mathrm{PaO}_{2} / \mathrm{FiO}_{2}$ increases proportionally to gas flow, especially between 10 and $30 \mathrm{~L} / \mathrm{min}$. As compared to standard oxygen, $50 \mathrm{~L} / \mathrm{min}$, but not $30 \mathrm{~L} / \mathrm{min}$ nor $10 \mathrm{~L} / \mathrm{min}$, ameliorate oxygenation and reduce respiratory rate in isocapnic conditions 

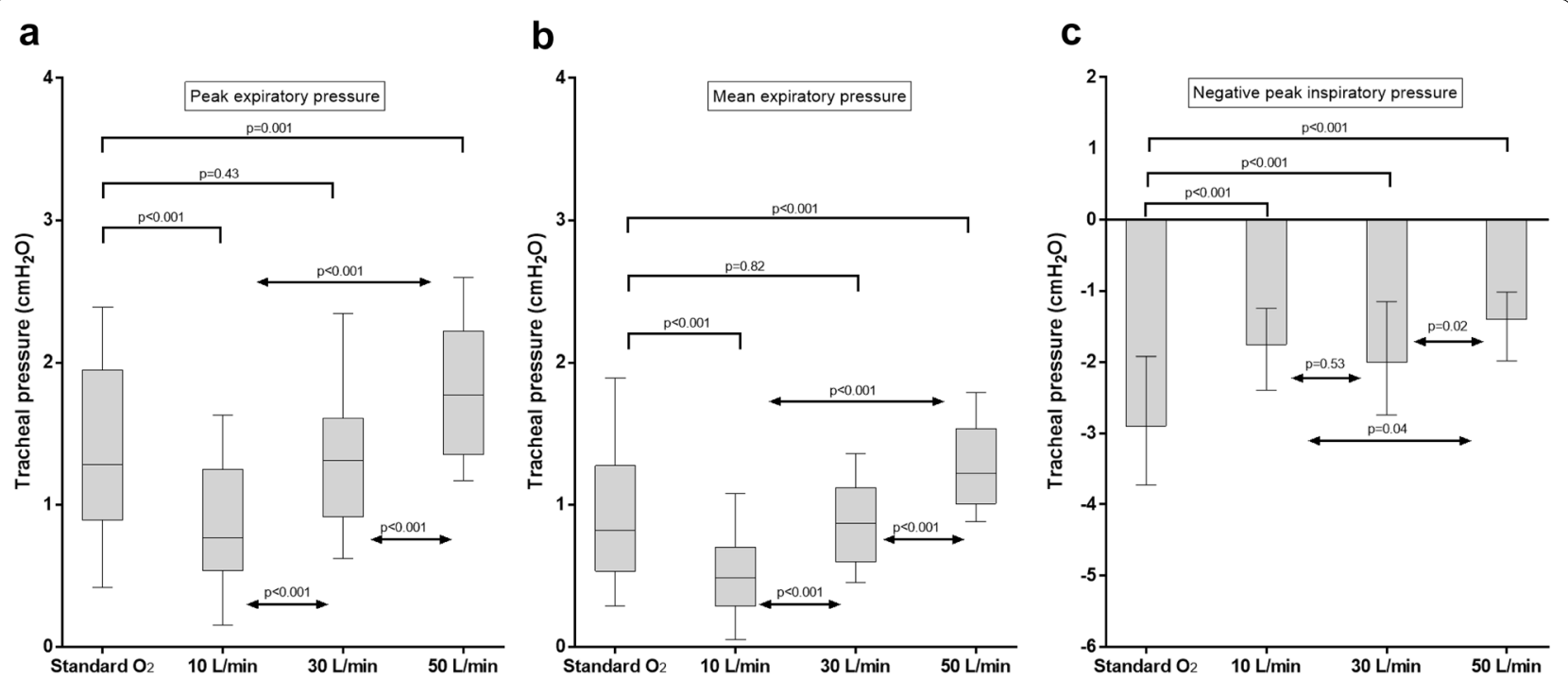

Fig. 2 Peak (a), mean expiratory pressure (b) and negative peak of inspiratory pressure. Results are displayed as median, interquartile range, maximum and minimum. During HFOT TRACHEAL, tracheal expiratory pressure increases proportionally to the gas flow. All HFOT TRACHEAL Settings limit the negative inspiratory pressure, especially as flow is set at $50 \mathrm{~L} / \mathrm{min}$, likely due to the capability of the high gas flow in an open system to match patient's peak inspiratory flow. As compared to standard oxygen, $50 \mathrm{~L} / \mathrm{min}$, but not $30 \mathrm{~L} / \mathrm{min}$ nor $10 \mathrm{~L} / \mathrm{min}$, increase tracheal peak and mean tracheal expiratory pressure

Fig. 3. Inter-individual variability in peak and mean expiratory pressure at $50 \mathrm{~L} / \mathrm{min}$ was greater during HFOT $_{\text {NASAL }}$ (both $35 \%$ ) than during HFOT $_{\text {TRACHEAL }}$ (21 and $20 \%$, respectively). Inspiratory pressure during $\mathrm{HFOT}_{\text {NASAL }} 50 \mathrm{~L} / \mathrm{min}$ fell below 0 during inspiration in $4 / 5$ patients. With all the tested flow settings, peak and mean expiratory tracheal pressures during $\mathrm{HFOT}_{\mathrm{NASAL}}$ were significantly higher than during $\mathrm{HFOT}_{\text {TRACHEAL }}$ (Fig. $4 ; p=0.05$ for all comparisons). In particular, with flow set at $50 \mathrm{~L} / \mathrm{min}$ : median peak expiratory pressure was 5.1 [4.2-7.7] $\mathrm{cmH}_{2} \mathrm{O}$ during HFOT $_{\text {NASAL }}$ vs. 1.8 [1.6-2.3] $\mathrm{cmH}_{2} \mathrm{O}$ during HFOT TRACHEAL $(p=0.05)$; mean expiratory pressure was 3.9 [3.1-6] $\mathrm{cmH}_{2} \mathrm{O}$ during $\mathrm{HFOT}_{\text {NASAL }}$ vs. 1.5 [1.2-1.7] $\mathrm{cmH}_{2} \mathrm{O}$ during HFOT $_{\text {TRACHEAL }}(p=0.05)$. The mean difference $[95 \%$ $\mathrm{CI}$ ] in tracheal peak and mean expiratory pressure between HFOT $_{\text {NASAL }}$ and HFOT TRACHEAL $_{\text {was }} 4$ [1-7] $\mathrm{cmH}_{2} \mathrm{O}$ and $3[1-5] \mathrm{cmH}_{2} \mathrm{O}$, respectively.

\section{Discussion}

In the present cross-over study, we show that, as com-

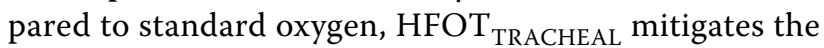
negative swing in airway pressure during inspiration, and, when flow is set at $50 \mathrm{~L} / \mathrm{min}$, ameliorates oxygenation and slightly reduces respiratory rate. With similar flow rates, tracheal expiratory pressure is significantly lower with $\mathrm{HFOT}_{\text {TRACHEAL }}$ than with $\mathrm{HFOT}_{\mathrm{NASAL}}$, suggesting that the physiologic effects of $\mathrm{HFOT}_{\text {TRACHEAL }}$ are milder than $\mathrm{HFOT}_{\mathrm{NASAL}}$. A gas flow of $50 \mathrm{~L} / \mathrm{min}$ should be set with the tracheal interface to slightly improve oxygenation and reduce respiratory rate.

Several studies addressed the effects of HFOT $_{\text {NASAL }}$ in a variety of clinical scenarii [1]. Although high-flow oxygen can be delivered through tracheostomy, few data elucidate its mechanisms of action, which can be different from HFOT $_{\text {NASAL }}[20]$.

\section{Oxygenation}

During $\mathrm{HFOT}_{\text {TRACHEAL }}, \mathrm{PaO}_{2} / \mathrm{FiO}_{2}$ ratio increases proportionally to gas flow. However, when compared to standard oxygen via heat and moisture exchangers, only $50 \mathrm{~L} / \mathrm{min}$ generate improvement in $\mathrm{PaO}_{2} / \mathrm{FiO}_{2}$ ratio. These data are partially consistent with what has been reported for $\mathrm{HFOT}_{\mathrm{NASAL}}$ [18] and may be explained by the following mechanisms:

1. Increasing flow rate up to $50 \mathrm{~L} / \mathrm{min}$ can limit air dilution of inhaled gas mixture, enabling more accurate delivery of set $\mathrm{FiO}_{2}$. This can be demonstrated by the reduction of the inspiratory airway pressure swing during HFOT $_{\text {TRACHEAL }}$.

2. Increasing flow rate yields a concomitant increase in peak and mean expiratory pressure. Although the increase in tracheal pressure generated by HFOT $_{\text {TRACHEAL }}$ is lower than the one reported during HFOT $_{\text {NASAL }}[11,14,15,28]$, this rise in expiratory pressure may still contribute to increase end-expir- 


\section{$50 \mathrm{~L} / \mathrm{min}$ \\ HFOT TRACHEAL}

\#9

\#16

$$
\text { il. }
$$
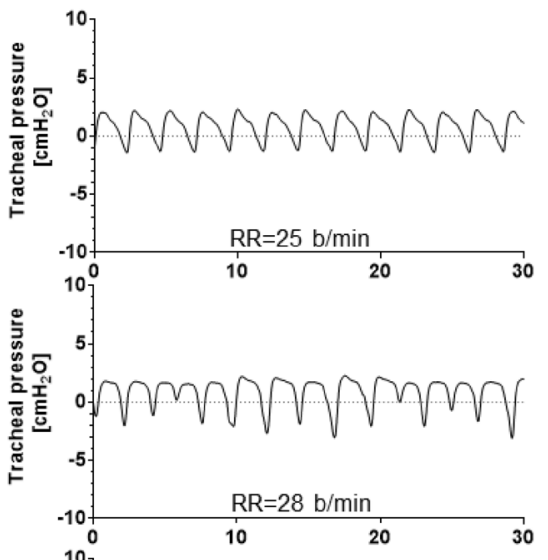

\#18

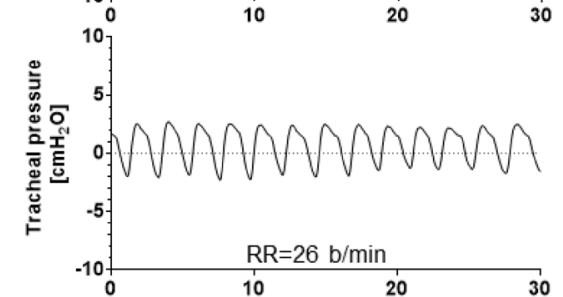

\#19
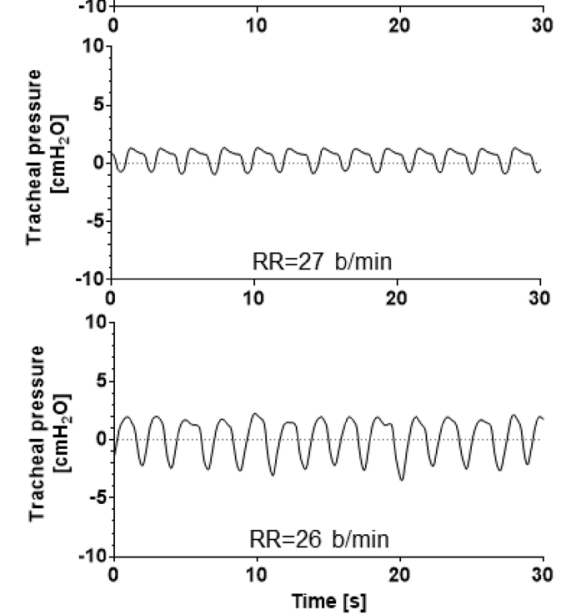

$50 \mathrm{~L} / \mathrm{min}$
HFOT $_{\text {NASAL }}$
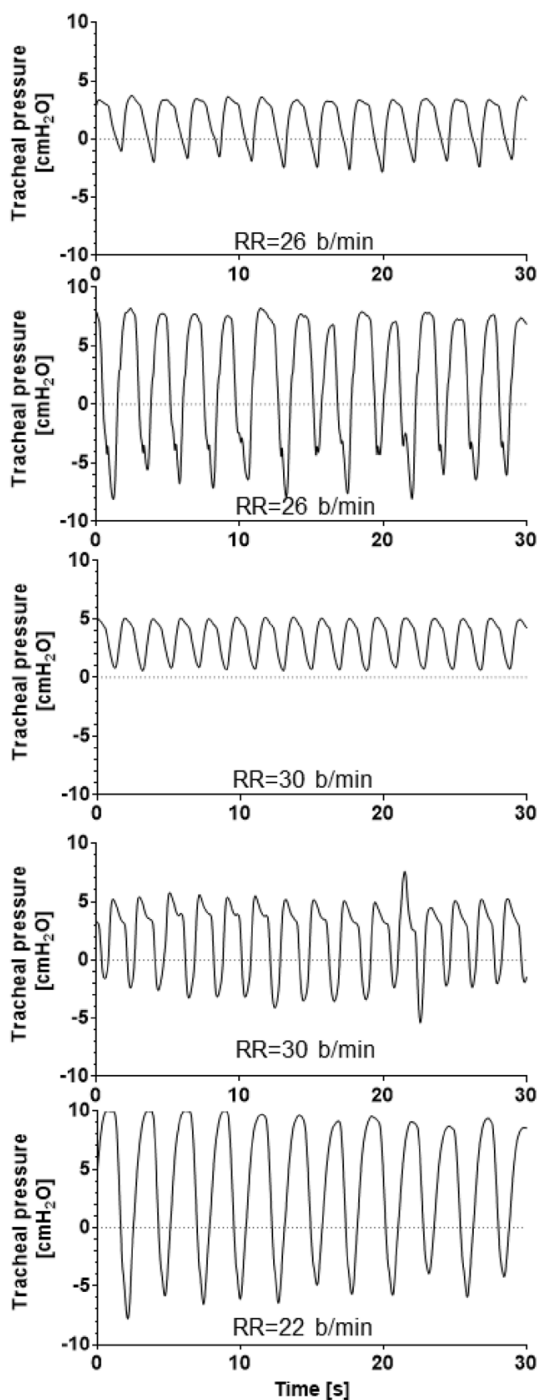

Fig. 3 Thirty-second recordings of tracheal pressure tracings during HFOT TRACHEAL and HFOT NASAL in 5 patients who underwent tracheostomy decannulation over the course of ICU stay. In both conditions gas flow was set at $50 \mathrm{~L} / \mathrm{min}$. Average respiratory rate for the 30-s recording

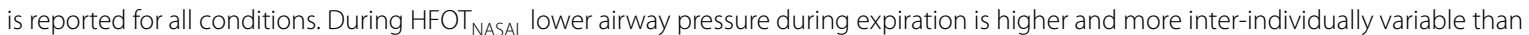
HFOT $_{\text {TRACHEAL, }}$ despite a non-dissimilar respiratory rate, which was calculated on the same 30-s recording. This suggests that the HFOT NASAL $^{- \text {induced }}$ increase in expiratory pressure depends not only on gas flow, but also on patient's expiratory pattern and, likely, on individual respiratory system mechanical properties. Please note that, under this condition, tracheal pressure was not constant over the course of the respiratory cycle and became negative during inspiration in 4 patients, which is different from what previously reported for pharyngeal pressure [14]

atory lung volume, reduce shunt fraction, optimize lung mechanics and improve oxygenation $[11,13,18$, 29].

One previous report showed that, when compared to T-Piece with a Venturi generator in tracheostomized patients, airway pressure and $\mathrm{SpO}_{2} / \mathrm{FiO}_{2}$ slightly increase during $50 \mathrm{~L} / \mathrm{min} \mathrm{HFOT}_{\text {TRACHEAL }}$ [20]. However, because of the entrainment effect, Venturi systems can provide flows up to $30-50 \mathrm{~L} / \mathrm{min}$ and cannot be considered standard oxygen devices [30]. Standard oxygen through heat and moisture exchangers represents a widely used alternative for oxygen therapy in tracheostomized patients. 


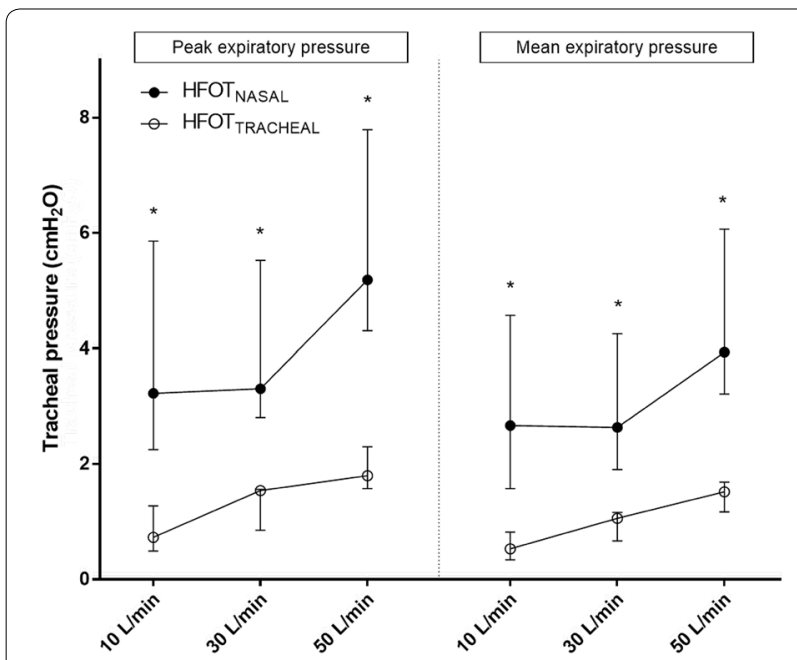

Fig. 4 Peak and mean expiratory pressure during HFOT TRACHEAL and HFOT $_{\text {NASAL }}$ and different gas flows delivered. Results are displayed as median and interquartile range; ${ }^{*}$ indicates $p \leq 0.05$ for HFOT TRACHEAL vs. HFOT NASAL $_{\text {Comparisons }}$

We have shown that standard oxygen through heat and moisture exchangers produces positive expiratory pressure, which is comparable to the one obtained with $30 \mathrm{~L} / \mathrm{min}$ of high-flow oxygen through an open system. In fact, oxygenation between these two settings was similar. For the same gas flow $(\approx 10 \mathrm{~L} / \mathrm{min})$, oxygenation and tracheal expiratory pressure were higher with the standard oxygenation (closed system) than with the HFOT $_{\text {TRACHEAL }}$ device (open system). This suggests that the oxygenation changes are dependent on the amount of tracheal expiratory pressure. However, mechanisms of airway pressure generation may be different between the two devices: with standard oxygen, the increase in pressure depends on the expiratory resistance produced by the heat and moisture exchanger; while, during HFOT $_{\text {TRACHEAL }}$, positive expiratory pressure is produced by patient's expiration against the delivered gas flow in an open system and airway pressure is more stable over the respiratory cycle (i.e., less negative during inspiration). In this context, avoidance of excessive negative inspiratory swings in airway (and pleural) pressure is important to mitigate the risk of negative pressure pulmonary edema, whose occurrence induces lung damage and worsens oxygenation [31].

\section{$\mathrm{CO}_{2}$ clearance}

HFOT $_{\text {NASAL }}$ lowers inspiratory resistance and enhances anatomical dead space clearance with $\mathrm{CO}_{2}$ washout [32, 33], finally reducing work of breathing [11, 13, 27, 34]. Our study shows that $50 \mathrm{~L} / \mathrm{min}$ HFOT $_{\text {TRACHEAL }}$ lowers respiratory rate without changes in $\mathrm{PaCO}_{2}$, as compared to standard oxygen. A reduction in respiratory rate has been reported during $\mathrm{HFOT}_{\text {NASAL }}[5,35]$ and has been linked to anatomical dead space clearance, increased tidal volume, diminished resistive work of breathing and, in chronic obstructive pulmonary disease patients, increased positive expiratory pressure [13, 33, 36].

Work of breathing reduction by HFOT $_{\text {NASAL }}$ is obtained at $30 \mathrm{~L} / \mathrm{min}$ and is minimally enhanced by further increases in gas flow [18]: differently, $50 \mathrm{~L} / \mathrm{min}$ of HFOT $_{\text {TRACHEAL }}$ are needed to generate effects on respiratory rate. It is, therefore, reasonable to hypothesize that, in tracheostomized patients:

1. lower anatomical dead space and inspiratory resistance reduce the size effect of the intervention, that consequently requires higher flows to generate a significant effect;

2. inspired and expired flows are forcedly unidirectional, thus clearing anatomical dead space and improving breathing efficiency [37]: this contributes to $\mathrm{CO}_{2}$ washout independently from the device used for oxygen therapy, thereby mitigating the effect of HFOT $_{\text {TRACHEAL }}$

Our results are consistent with recent data indicating that HFOT $_{\text {TRACHEAL minimally affects neuro-ventilatory }}$ coupling, work of breathing and gas exchange after weaning from mechanical ventilation [19].

\section{Differences with HFOT NASAL $_{\text {}}$}

Our comparison of HFOT TRACHEAL $_{\text {and HFOT }}$ NASAL in the same patients represented a unique opportunity to highlight the contribution of upper airway resistance to positive-pressure generation during $\mathrm{HFOT}_{\text {NASAL }}$. In fact, to our knowledge, no other data clarify the behavior of lower airway pressure during this treatment. The average expiratory pressure reported in our study is similar to what has been reported for pharyngeal pressure [11, $15,28]$. However, tracheal pressure during HFOT $_{\text {NASAL }}$ was not constant over the respiratory cycle and became negative during inspiration in 4 of the 5 studied patients, which is different from what has been reported on upper airway pressure [14]. Our results indicate that expiratory pressure in lower airways is higher and more inter-individually variable when high flows are delivered through nasal cannula than through tracheostomy. This suggests that the mechanism of expiratory pressure generation during high-flow oxygen is dependent not only on gas flow rate, but also on the greater resistance offered by upper airways and patient's expiratory flow. In tracheostomized patients, resistance is limited, and the generated pressure is minimal. Patient's expiratory flow has wide inter-individual variability according to the resistive and 
elastic properties of the respiratory system and to the eventual recruitment of expiratory muscles [38]: thus, the pressure produced by HFOT $_{\text {NASAL }}$ is variable among subjects, also if respiratory rate with HFOT $_{\text {TRACHEAL }}$ is similar (Fig. 3) [39].

\section{Clinical consequences}

Our study shows that the effects of HFOT $_{\text {TRACHEAL }}$ are milder than HFOT $_{\text {NASAL }}$, likely because the dedicated

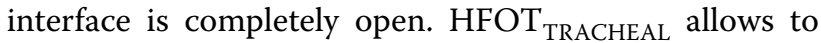
limit the negative swing in inspiratory airway pressure, but both the dead space washout and the generation of positive expiratory pressure are limited. From a clinical perspective, our findings suggest that a minimum gas flow of $50 \mathrm{~L} / \mathrm{min}$ should be set during HFOT $_{\text {TRACHEAL }}$ to slightly improve oxygenation and reduce respiratory rate, as compared to standard oxygen. Whether these mild physiologic effects are cost-effective and may clinically benefit the management of tracheostomized patients cannot be established from our data and should be addressed in further investigations.

\section{Limitations}

First, we did not measure effectively delivered $\mathrm{FiO}_{2}$, as performed elsewhere [3]. As a result, the calculation of $\mathrm{PaO}_{2} / \mathrm{FiO}_{2}$ ratio may be subject to errors, especially if lower flows are used [40]. Nevertheless, our approach is clinically reproducible and we used a formula that has recently been shown to provide satisfactory correlation with actual $\mathrm{FiO}_{2}$ [24].

Second, we did not measure work of breathing by esophageal manometry [41]. However, esophageal catheter insertion in awake and spontaneously breathing patients may be challenging and eventually require some sedation. Importantly, during HFOT $_{\text {NASAL }}$ changes in respiratory rate have been shown to reflect variations of the work of breathing $[13,33]$.

Third, there was no wash-out period between the applied interventions during HFOT $_{\text {TRACHEAL How- }}$ ever, our approach is consistent with previous investigations on the topic [18], and the randomized order of the interventions should have mitigated any carryover effect on the observed results. Accordingly, the main outcomes of the study were not affected by the sequence of applied flow settings.

Fourth, during HFOT $_{\text {NASAL }}$, absence of major leaks through the stoma was assessed by hand. Unfortunately, we had no other way to assess if minimal leaks were present. We believe, however, that even minimal leaks, if present, should not have affected tracheal pressure measurement. In fact, the tracheal pressure values we report are similar to nasopharyngeal pressure values measured in non-tracheostomized patients by others [13-15].

Finally, we showed that expiratory pressure increase due to HFOT $_{\text {NASAL }}$ has wide inter-individual variability. Whether and to what extent expiratory flow limitation and expiratory muscles recruitment contribute to this is unknown and remains to be established in further investigations [38, 42].

\section{Conclusions}

HFOT $_{\text {TRACHEAL generates small flow-dependent }}$ improvement in oxygenation and increases in tracheal expiratory pressure. When compared to standard oxygen, a minimum flow of $50 \mathrm{~L} / \mathrm{min}$ is needed during HFOT $_{\text {TRACHEAL }}$ to improve oxygenation, increase expiratory pressure, limit inspiratory airway pressure swings and reduce respiratory rate. At same gas flow, HFOT $_{\text {NASAL }}$ produces higher expiratory pressure than HFOT $_{\text {TRACHEAL }}$.

\section{Acknowledgements}

None.

\section{Authors' contributions}

DN, DLG and SMM designed the study. DN, MTS, FT, GMA, DE enrolled the patients and recorded the data. LM and DLG analyzed the data. DN and PDG interpreted results and drafted the manuscript. SMM and MA critically revised the manuscript. All authors read and approved the final manuscript.

\section{Funding}

This research did not receive any specific grant from funding agencies in the public, commercial, or not-for-profit sectors. Support was provided solely from institutional and/or departmental sources. Outside of the present work, Dr. Grieco is supported by research Grants by SIAARTI and ESICM.

\section{Availability of data and materials}

The datasets used and/or analyzed during the current study are available from the corresponding author on reasonable request.

\section{Ethics approval and consent to participate}

The study was approved by local Ethics Committee (ID 25533/16) and written informed consent to data analysis was obtained by all studied patients.

\section{Competing interests}

DLG has received payments for travel expenses by Maquet, Getinge and Air Liquide. MA has received payments for Board participation from Maquet, Air Liquide and Chiesi. DLG and MA disclose a research grant by General Electric Healthcare. SMM is the principal investigator of the RINO trial (clinicaltrials.gov, NCT02107183), which was supported by Fisher and Paykel healthcare.

\section{Author details}

${ }^{1}$ Department of Anesthesiology and Intensive Care, Catholic University of the Sacred Heart, Fondazione'Policlinico Universitario A. Gemelli' IRCCS, Rome, Italy. ${ }^{2}$ Department of Medical, Oral and Biotechnological Sciences, School of Medicine and Health Sciences, Section of Anesthesia Analgesia, Perioperative and Intensive Care, SS. Annunziata Hospital, Gabriele d'Annunzio University of Chieti-Pescara, Via dei Vestini, 66100 Chieti, Italy.

Received: 25 June 2019 Accepted: 30 September 2019

Published online: 07 October 2019 


\section{References}

1. Papazian L, Corley A, Hess D, Fraser JF, Frat J-P, Guitton C, et al. Use of high-flow nasal cannula oxygenation in ICU adults: a narrative review. Intensive Care Med. 2016;42:1336-49.

2. Roca O, Hernández G, Díaz-Lobato S, Carratalá JM, Gutiérrez RM, Masclans $J R$, et al. Current evidence for the effectiveness of heated and humidified high flow nasal cannula supportive therapy in adult patients with respiratory failure. Crit Care. 2016;20:109.

3. Frat J-P, Thille AW, Mercat A, Girault C, Ragot S, Perbet S, et al. High-flow oxygen through nasal cannula in acute hypoxemic respiratory failure. $\mathrm{N}$ Engl J Med. 2015;372:2185-96.

4. Frat J-P, Ragot S, Girault C, Perbet S, Prat G, Boulain T, et al. Effect of noninvasive oxygenation strategies in immunocompromised patients with severe acute respiratory failure: a post hoc analysis of a randomised trial. Lancet Respir Med. 2016;4:646-52.

5. Maggiore SM, Idone FA, Vaschetto R, Festa R, Cataldo A, Antonicelli F, et al. Nasal high-flow versus Venturi mask oxygen therapy after extubation. Effects on oxygenation, comfort, and clinical outcome. Am J Respir Crit Care Med. 2014;190:282-8.

6. Hernández G, Vaquero C, González P, Subira C, Frutos-Vivar F, Rialp G, et al. Effect of postextubation high-flow nasal cannula vs conventional oxygen therapy on reintubation in low-risk patients: a randomized clinical trial. JAMA. 2016;315:1354-61.

7. Stéphan F, Barrucand B, Petit P, Rézaiguia-Delclaux S, Médard A, Delannoy $B$, et al. High-flow nasal oxygen vs noninvasive positive airway pressure in hypoxemic patients after cardiothoracic surgery: a randomized clinical trial. JAMA. 2015;313:2331-9.

8. Fernandez R, Subira C, Frutos-Vivar F, Rialp G, Laborda C, Masclans JR, et al. High-flow nasal cannula to prevent postextubation respiratory failure in high-risk non-hypercapnic patients: a randomized multicenter trial. Ann Intensive Care. 2017:7:47.

9. Vourc'h M, Asfar P, Volteau C, Bachoumas K, Clavieras N, Egreteau P-Y, et al. High-flow nasal cannula oxygen during endotracheal intubation in hypoxemic patients: a randomized controlled clinical trial. Intensive Care Med. 2015;41:1538-48.

10. Miguel-Montanes R, Hajage D, Messika J, Bertrand F, Gaudry S, Rafat C, et al. Use of high-flow nasal cannula oxygen therapy to prevent desaturation during tracheal intubation of intensive care patients with mild-tomoderate hypoxemia. Crit Care Med. 2015:43:574-83.

11. Parke RL, Bloch A, McGuinness SP. Effect of very-high-flow nasal therapy on airway pressure and end-expiratory lung impedance in healthy volunteers. Respir Care. 2015;60:1397-403.

12. Chanques G, Riboulet F, Molinari N, Carr J, Jung B, Prades A, et al. Comparison of three high flow oxygen therapy delivery devices: a clinical physiological cross-over study. Minerva Anestesiol. 2013;79:1344-55.

13. Mauri T, Turrini C, Eronia N, Grasselli G, Volta CA, Bellani G, et al. Physiologic effects of high-flow nasal cannula in acute hypoxemic respiratory failure. Am J Respir Crit Care Med. 2017;195:1207-15.

14. Parke RL, McGuinness SP. Pressures delivered by nasal high flow oxygen during all phases of the respiratory cycle. Respir Care. 2013;58:1621-4

15. Parke R, McGuinness S, Eccleston M. Nasal high-flow therapy delivers low level positive airway pressure. Br J Anaesth. 2009;103:886-90.

16. Möller W, Feng S, Domanski U, Franke K-J, Celik G, Bartenstein P, et al. Nasal high flow reduces dead space. J Appl Physiol. 2017;122:191-7.

17. Mauri T, Galazzi A, Binda F, Masciopinto L, Corcione N, Carlesso E, et al. Impact of flow and temperature on patient comfort during respiratory support by high-flow nasal cannula. Crit Care. 2018;22:120.

18. Mauri T, Alban L, Turrini C, Cambiaghi B, Carlesso E, Taccone P, et al. Optimum support by high-flow nasal cannula in acute hypoxemic respiratory failure: effects of increasing flow rates. Intensive Care Med. 2017;43:1453-63.

19. Stripoli T, Spadaro S, Di Mussi R, Volta CA, Trerotoli P, De Carlo F, et al. High-flow oxygen therapy in tracheostomized patients at high risk of weaning failure. Ann Intensive Care. 2019:9:4.

20. Corley A, Edwards M, Spooner AJ, Dunster KR, Anstey C, Fraser JF. Highflow oxygen via tracheostomy improves oxygenation in patients weaning from mechanical ventilation: a randomised crossover study. Intensive Care Med. 2017:43:465-7.

21. Natalini D, Idone F, Grieco D, Spaziani L, Santantonio M, Toni F, et al. Impact of high-flow oxygen therapy delivered through a tracheostomy on arterial blood gases and endotracheal pressure. Crit Care. 2014;18:P321.

22. Yurtseven N, Aydemir B, Karaca P, Aksoy T, Komurcu G, Kurt M, et al. PercuTwist: a new alternative to Griggs and Ciaglia's techniques. Eur J Anaesthesiol. 2007:24:492-7.

23. Frova G, Quintel M. A new simple method for percutaneous tracheostomy: controlled rotating dilation. A preliminary report. Intensive Care Med. 2002;28:299-303.

24. Coudroy R, Thille AW, Drouot X, Diaz V, Meurice J-C, Robert R, et al. How to assess $\mathrm{FiO} 2$ delivered under oxygen mask in clinical practice? Intensive Care Med Exp. 2017:5:0968.

25. O'Connor HH, White AC. Tracheostomy decannulation. Respir Care. 2010;55:1076-81.

26. Reed GF, Lynn F, Meade BD. Use of coefficient of variation in assessing variability of quantitative assays. Clin Diagn Lab Immunol. 2002;9:1235-9.

27. Delorme M, Bouchard P-A, Simon M, Simard S, Lellouche F. Effects of high-flow nasal cannula on the work of breathing in patients recovering from acute respiratory failure. Crit Care Med. 2017;45:1981-8.

28. Parke R, Eccleston M, McGuinness S. The effects of flow on airway pressure during nasal high-flow oxygen therapy. Respir Care. 2011;56:1151-5.

29. Corley A, Caruana LR, Barnett AG, Tronstad O, Fraser JF. Oxygen delivery through high-flow nasal cannulae increase end-expiratory lung volume and reduce respiratory rate in post-cardiac surgical patients. Br J Anaesth. 2011;107:998-1004

30. Wong GL, Finnis ME. Use of venturi entrainment to deliver nasal high fow oxygen. Crit Care Shock. 2010;13:75-80.

31. Yoshida T, Fujino Y, Amato MBP, Kavanagh BP. Fifty years of research in ARDS. Spontaneous breathing during mechanical ventilation. Risks, mechanisms, and management. Am J Respir Crit Care Med. 2017;195:985-92.

32. Möller W, Celik G, Feng S, Bartenstein P, Meyer G, Oliver E, et al. Nasa high flow clears anatomical dead space in upper airway models. J Appl Physiol. 2015;118:1525-32.

33. Chatila W, Nugent T, Vance G, Gaughan J, Criner GJ. The effects of highflow vs low-flow oxygen on exercise in advanced obstructive airways disease. Chest. 2004;126:1108-15.

34. Sklar MC, Dres M, Rittayamai N, West B, Grieco DL, Telias I, et al. High-flow nasal oxygen versus noninvasive ventilation in adult patients with cystic fibrosis: a randomized crossover physiological study. Ann Intensive Care. 2018;8:85.

35. Fraser JF, Spooner AJ, Dunster KR, Anstey CM, Corley A. Nasal high flow oxygen therapy in patients with COPD reduces respiratory rate and tissue carbon dioxide while increasing tidal and end-expiratory lung volumes: a randomised crossover trial. Thorax. 2016:71:759-61.

36. Mündel T, Feng S, Tatkov S, Schneider H. Mechanisms of nasal high flow on ventilation during wakefulness and sleep. J Appl Physiol. 2013:114:1058-65.

37. Jiang $Y$, Liang $Y$, Kacmarek RM. The principle of upper airway unidirectional flow facilitates breathing in humans. J Appl Physiol. 2008;105:854-8.

38. Junhasavasdikul D, Telias I, Grieco DL, Chen L, Gutierrez CM, Piraino T, et al. Expiratory flow limitation during mechanical ventilation. Chest. 2018;154:948-62.

39. Lessard MR, Lofaso F, Brochard L. Expiratory muscle activity increases intrinsic positive end-expiratory pressure independently of dynamic hyperinflation in mechanically ventilated patients. Am J Respir Crit Care Med. 1995;151:562-9.

40. Sztrymf B, Messika J, Bertrand F, Hurel D, Leon R, Dreyfuss D, et al. Beneficial effects of humidified high flow nasal oxygen in critical care patients: a prospective pilot study. Intensive Care Med. 2011:37:1780-6.

41. Akoumianaki E, Maggiore SM, Valenza F, Bellani G, Jubran A, Loring SH, et al. The application of esophageal pressure measurement in patients with respiratory failure. Am J Respir Crit Care Med. 2014;189:520-31.

42. Shi Z-H, Jonkman A, de Vries H, Jansen D, Ottenheijm C, Girbes A, et al. Expiratory muscle dysfunction in critically ill patients: towards improved understanding. Intensive Care Med. 2019:45:1061-71.

\section{Publisher's Note}

Springer Nature remains neutral with regard to jurisdictional claims in published maps and institutional affiliations. 